\title{
Article Delivery Service
}

Our abstracting service is intended to provide the flavour of the best and most relevant articles we have found in contemporary publications. This is no substitute for reading the original, where it is relevant to your concerns, therefore:

The IDM Knowledge Centre can deliver, by post or fax, a copy of most of the articles abstracted, this service is FREE to IDM members; non-members pay a handling fee of $£ 15$ per article with a maximum handling fee for any one order of $£ 60$.

The law in the UK requires that you sign a copyright declaration before copies can be despatched:

- If the article is for non-commercial research or for private study, no copyright fee is payable, but you may only have one article from each lettered group below.

- If the article is for a commercial purpose the appropriate copyright fee must be paid - fees are given next to the abstract number below.

- For help in deciding whether your purpose is commercial or non-commercial, please contact the IDM Knowledge Centre, or look at the guidance provided by the British Library at www.bl.uk/ services/information/copyrightfaq.html

\section{To order}

When you know whether your purpose is commercial or not, ask the Knowledge Centre to e-mail, fax or post you the appropriate order form.

\section{Contacting the IDM Knowledge Centre}

Telephone: +44 (0) 2086140253

E-mail: knowledgecentre@theidm.com

Post: $\quad$ Knowledge Centre, IDM, 1 Park Road, Teddington TW11 0AR, UK

The Knowledge Centre is staffed on Mondays and Tuesdays by Penny Crossland and on Wednesdays to Fridays by Anita Littler.

\section{Copyright Fees and Lettered Groups}

All fees are subject to VAT at 17.5\%. Copyright Fees correct at 16 March 2006.

\begin{tabular}{|lll|lll|lll|lll|lll|}
\hline $\mathbf{7 4 0 1}$ & $\mathrm{N} / \mathrm{A}$ & & $\mathbf{7 4 0 6}$ & $£ 5$ & $\mathrm{D}$ & $\mathbf{7 4 1 1}$ & $£ 13$ & $\mathrm{H}$ & $\mathbf{7 4 1 6}$ & $£ 13$ & $\mathrm{M}$ & $\mathbf{7 4 2 1}$ & $£ 5$ & $\mathrm{Q}$ \\
$\mathbf{7 4 0 2}$ & $£ 13$ & $\mathrm{~A}$ & $\mathbf{7 4 0 7}$ & $£ 5$ & $\mathrm{E}$ & $\mathbf{7 4 1 2}$ & $£ 13$ & $\mathrm{~J}$ & $\mathbf{7 4 1 1 7}$ & $£ 13$ & $\mathrm{~N}$ & & & \\
$\mathbf{7 4 0 3}$ & $£ 5$ & $\mathrm{~B}$ & $\mathbf{7 4 0 8}$ & $£ 5$ & $\mathrm{~F}$ & $\mathbf{7 4 1 3}$ & $£ 13$ & $\mathrm{~K}$ & $\mathbf{7 4 1 8}$ & $£ 22$ & $\mathrm{P}$ & & & \\
$\mathbf{7 4 0 4}$ & $£ 17$ & $\mathrm{C}$ & $\mathbf{7 4 0 9}$ & $£ 5$ & $\mathrm{~F}$ & $\mathbf{7 4 1 4}$ & $£ 13$ & $\mathrm{~L}$ & $\mathbf{7 4 1 9}$ & $£ 17$ & $\mathrm{C}$ & & & \\
$\mathbf{7 4 0 5}$ & $£ 5$ & $\mathrm{D}$ & $\mathbf{7 4 1 0}$ & $£ 13$ & $\mathrm{G}$ & $\mathbf{7 4 1 5}$ & $£ 13$ & $\mathrm{~L}$ & $\mathbf{7 4 2 0}$ & $£ 5$ & $\mathrm{Q}$ & & & \\
\hline
\end{tabular}

$\mathfrak{E V}$ means a photocopy for commercial purpose is not available but visitors may read the article in the Knowledge Centre (by appointment, please).

n/a means a photocopy is not available but visitors may read the article in the Knowledge Centre (by appointment, please). 
The bold items in the margin describe the subject matter and are keywords for text retrieval. The final reference number under each abstract is also used for this purpose (see reprint service on $p .356)$

VoIP, telephony, internet, Wi-Fi, Skype, SAP

\section{Abstracts}

Each abstracted article is awarded 0-5 stars for each of four qualities:

(1) depth of research

(2) value in practice

(3) originality of thinking

(4) readability for non-specialists.

No abstract is included for any article awarded less than seven stars overall.

\section{Internet telephony}

Anon.

TeChnological and Journalistic. The Times (UK), Supplement 7 December 2005 (32pp)

Comprises a series of articles on voice over internet protocol (VoIP) covering what is VoIP?; VoIP and business; what about Skype?; how do I get it?; why and how; the VoIP maze; state of the art?; panel of experts; SAP boosts network; when the chips are down; voice over WiFi; security; VoIP with no strings; we're talking telephone numbers. Claims that VoIP offers huge cost savings and enhanced productivity: with a telephone number that is also an IP address, anyone can be reached at any time, anywhere, with one call to a single number. Notes that most telephone calls already travel at some stage over an IP network. Describes the concept of package switching. Emphasises that calls within the IP network are free; calls from the network to outside cost a fraction of current charges. Claims that VoIP is as reliable as landlines; within each office network voice is always given priority over data. Notes the arrival of Skype (recently purchased by eBay): claimed to be the fastest-growing internet company ever; it offers free software (now reaching 210 million downloads, and 180,000 more every day) giving free calls between broadband users, in-country calls to landlines at $1 \mathrm{p}$ per minute and international calls at local rates. Considers the costs of migrating to VoIP, and the choices involved. Discusses the possibility of mixed traditional and IP systems. Gives a VoIP case study from SAP (a major independent software company). And much more...

Really a must-read for any business not already possessed of expert knowledge and skills in this area. An excellent summary of the present position and future potential of this telephonic revolution.

Research: —_ Practice: $* * * * *$ Originality: —— Readability: $* * * * * *$ Ref: 7401 
Advertising, pharmaceuticals, DTC

\section{For the drugs we need}

\section{H. J. Rotfeld}

JOURNALISTIC. Journal of Consumer Marketing (UK), Vol. 22, No. 7, p. $365(4 \mathrm{pp})$

Sets out to examine criticisms of pharmaceutical advertising — in the first instance to doctors, and later (based on experience from the USA and New Zealand) direct to consumers (DTC). Notes the provision by pharmaceutical companies of gifts and freebies to doctors. Doubts the effect of this, but finds doctors may be misled by incorrect data in ads. Notes the dramatic increase in diagnoses of a condition whenever a new drug to alleviate that condition is announced. Notes the conflict between branded drugs and (after patent expiry) cheaper generic products. Considers the consequences of a ban on all brand names on pharmaceuticals. Notes the continuing debate on DTC advertising (now involving Europe, including the UK) and that heavy regulatory requirements on full disclosure of information on prescription-only drugs lead to a check on DTC advertising by increasing printing costs. Claims that the object of DTC advertising is to establish brand recognition which will last beyond the patent period. Questions the value, to any party, of DTC advertising.

This whole issue of Consumer Marketing is devoted to pharmaceutical marketing. (For more in other journals, see abstracts in our Vol. 6, Nos 1, 2 and 3, refs 6106, 6220 and 6321.) Not only is the DTC issue a live one in Europe, but the whole debate raises, in a sensitive area, issues about advertising as a whole.

Research: $* \quad$ Practice: $* * \quad$ Originality: $* * \quad$ Readability: $* * *$ Ref: 7402

\section{Marketing malpractice: The cause and the cure}

C. M. Christensen, S. Cook and T. Hall

THEORETICAL, WITH EXAMPLES. Harvard Business Review (USA), December 2005, p. 74 (10pp)

Notes that of 30,000 new product launches each year, over 90 per cent fail. Claims this is because traditional methods of segmenting markets, building brands and understanding customers are broken - a new model is needed. Refers to Levitt's dictum that customers do not want drills, they want holes - yet marketers still segment their markets by type of drill, and measure market share of drills, not holes. Claims segmenting by type of customer is no better: customers' desires do not conform to those of an 'average' customer in some demographic segment. Holds that the fundamental unit of analysis should be the job that needs to be done, rather than the customer or the product. (Notes rare occasions when the job and the customer are closely aligned - eg female hygiene, or baby care: these are the exception.) Gives examples of the development of jobfocused 'purpose brands' (eg FedEx). Discusses the case of disruptive innovations - eg the one-time camera by Kodak. Notes the case of brands designed to do aspirational rather than functional jobs - eg 
Gucci. Considers the role of advertising is to clarify the nature of the job the product is designed to do: claims most great brands were built before their owners started advertising much. Claims that much brand-building advertising is money wasted on a grand scale: instances car manufacturers (with exceptions for Range Rover, Rolls Royce and other aspirational brands). Considers the problems and opportunities of brand extensions.

One or two of the numerous illustrative examples are trivial and unconvincing, but the main thesis, derived from Ted Levitt, is spot on, and the resulting criticism of mindless brand advertising, especially of cars, is long overdue.

Research: $* * \quad$ Practice: $* * *$ Originality: $* * \quad$ Readability: $* * *$ Ref: 7403

\section{New product development, NPD, co-creation}

\section{Collaborating to create: The internet as a platform for customer engagement in product innovation}

M. Sawhney, G. Verona and E. Prandelli

SURVEY. Journal of Interactive Marketing (USA), Vol. 19, No. 4, p. 4 (14pp)

Notes the increasing use of the internet as a platform for co-creating value through dialogue with customers. Looks at traditional methods of new product development (NPD), including at the front end focus groups, surveys and conjoint analysis, and at the back end prototyping, product testing and test marketing. Characterises traditional methods as firmcentric, with uni-directional information flows and a bias towards current, large, customers. Notes the ability of the internet to reduce the trade-off between richness and reach in the acquisition of information.

Distinguishes two dimensions of customer involvement in NPD: richness versus reach, and front-end versus back-end development. Looks at possibilities for suggestion boxes, advisory panels, virtual communities, idea markets (all front end and high richness); online surveys, conjoint analysis, listening-in (all high reach and front end); toolkits for users' innovation (back end, high richness); mass customisation, virtual product and market testing (back end, high reach). Introduces two case studies: an Italian motor-cycle manufacturer (Ducati) and a US pharmaceutical company (Eli Lilley). Examines the performance of each in relation to this two-dimensional matrix. Emphasises that the internet should be an integrated platform for multiple devices, and that these devices are synergistic, not discrete silos. Claims that this way of working also involves organisational change for firms. Refers to Lilley's experience in creating InnoCentive, first as a platform offering rewards to scientists who would solve specific problems for Lilley, then as an autonomous marketplace facilitating collaborative invention for any participating company.

A fascinating insight (albeit a little fuzzy on detail) into the almost-now and certain future of new product development (and why stop there?). 


\section{Advertising, brands, mature markets}

Research: $* * * *$ Practice: $* * * *$ Originality: $* \quad$ Readability: $* * * *$ Ref: 7404

\section{Defending brand advertising's share of voice: A mature market(s) perspective}

L. Eagle, P. J. Kitchen and L. Rose

CONTROVERSIAL. Journal of Brand Management (UK), Vol. 13, No. 1, p. $65(15 \mathrm{pp})$

Notes the belief, among both marketers (particularly in the USA) and legislators generally, in the enormous persuasive power of advertising; finds that all recent research tends to the view that advertising in a mature market is a zero-sum game which does not affect the size of the market but operates only to enable companies to maintain their market share, or perhaps increase it at competitors' expense; the effects, therefore, of advertising on consumption patterns are relatively weak. Traces the background theory that gives rise to this view, including considerations of customer inertia, advertising saturation and diminishing incremental returns. Looks briefly at studies of alcohol and tobacco sales. Quotes Flandin as saying money is spent on advertising 'only because the manufacturer or retailer does not know of a more efficient way of generating sales'. Considers these theories in relation to the fast-food market in New Zealand. Shows advertising expenditure from 1995 to 2003 in various branded outlets. Suggests that, after allowing for inflation, expenditure has not significantly increased, while increased sales in fastfood outlets have roughly kept pace with population growth. Concludes that, in this (and by extension others) mature market, individual brand advertising is maintained just above inflation; market size is unchanged; advertising is a weak reminder force, not a powerful persuader.

Of course, if this thesis is right, then banning all advertising in mature markets would hurt no one and benefit everyone (except advertising agencies). Does this mean that those who used this argument to fight the advertising ban on tobacco did not believe their own argument, or were too stupid to understand its implications?

Research: $* * *$ Practice: $* * \quad$ Originality: $* * \quad$ Readability: $* * *$ Ref: 7405

\section{The curse of brand narcissism}

\section{A. Mitchell}

THEORETICAL. Journal of Brand Management (UK), Vol. 13, No. 1, p. 4 (6pp)

Suggests three 'holy trinity' building blocks of brand success: adding value and delivering superior margins; differentiation in customers' eyes; communications which drive sales and loyalty. Suggests that within these three lurks a dangerous disease - brand narcissism, which uses the processes of brand management, intended to create company-consumer win-win situations, but leads in the opposite direction. Looks first at the 
'lure of the premium': when the brand premium becomes the goal of brand building instead of a by-product, the true purpose of delivering superior value is edged out. Suggests that value-creating innovations quickly become incorporated into category basics: any remaining differentiators are simply features of little or no interest to customers. Claims, with Levitt, that what matters is the process of marketing, not just what is marketed; adding value should not be a matter of adding bells and whistles (which only makes room for own-label discounters), but of streamlining and simplifying. Claims secondly that 'customer focus' often means simply identifying and meeting those needs we already meet well - a product-centric, narcissistic strategy. Notes thirdly the conflict between identifying customer needs and altering customers' attitudes: where the second predominates, brand narcissism has taken over. Notes consumer resistance to this kind of advertising, but also consumer need for quality information. Lists a number of companies that are outstanding leaders in their fields: all have made breakthroughs in delivering new customer value, rather than in product formulation or communication strategy (eg Toyota, Dell, Wal-Mart).

Another (see previous abstract) well-considered attack on mindless advertising as a wasteful component of product-centric marketing.

Research: ** Practice: $* * *$ Originality: ** Readability: **** Ref: 7406

\section{Brands, globalisation}

\section{The post-global brand}

\section{J.-N. Kapferer}

THEORETICAL. Journal of Brand Management (UK), Vol. 12, No. 5, p. 319 (6pp)

Notes Professor Levitt's paper of 1983 entitled 'The globalisation of markets' in the Harvard Business Review as one of the most influential papers in business management, predicting the economies of scale available from the globalisation of production. Gives example of Nike and, contrariwise, of Moulinex. Claims, however, that product globalisation is something of a myth: illustrates from the car industry, where Ford's Model T was the most global product ever. Holds that upstream globalisation may still offer advantages, but that the nearer the customer one gets, the more one has to deal on a local or regional basis: we are in a 'post-global' era. Notes the US practice of pushing the global concept much harder than is European practice, and adduces reasons. Questions what it is that the idea of globalisation consists of: a brand is a three-sided system comprising a concept, a name and set of signs and a product/service. Holds there will often be good reasons for product globalisation, sometimes for a name/logo and other times for a concept. Suggests that perming these three sides gives eight possible structural types of approach to a global/local model. Elaborates on each of these types.

Post-modern, post-global — what next? Post-life perhaps? The discussion 
Financial services, marketing, branding is not uninteresting, but scarcely new: the mantra 'think global, act local' has been around for yonks.

Research: * Practice: $* * \quad$ Originality: ** Readability: *** Ref: 7407

\section{A survey of key success factors in financial services marketing and brand management \\ M. Hinshaw \\ SURVEY. Journal of Financial Services Marketing (UK), Vol. 10, No. 1, p. 37 (12pp)}

Notes a move among marketing and brand management professionals towards greater accountability; also that in many places executive management views marketing as a cost, not a revenue creator. Details a survey conducted by telephone with 67 senior marketing executives in US financial institutions to assess the challenges of improving marketing and brand performance, relevance, value and accountability. Indicates that half of respondents rated their firms' performance in both marketing and branding as somewhat effective, limited or not effective at all (as distinct from effective or extremely effective). Finds that in these cases marketing is being conducted without funding and/or commitment to tracking basic metrics. Indicates that 17 per cent of respondents do not track marketing metrics, and 47 per cent do not track branding activity. Describes a gap between those who rate the tracking of marketing and branding as important ( 80 per cent and 81 per cent respectively) and those who always or usually do it (60 per cent and 43 per cent). Lists the marketing metrics of importance to respondents as response rates, revenue generation and profit generation; important brand metrics are customer experience, retention and loyalty. Lists the top ten issues that would improve effectiveness, and the greatest challenges. Concludes with a series of recommendations.

Observation suggests that, while financial services are probably the worst offenders in this area (and in the UK as well as the USA), other sectors face identical problems with performance that is not in all cases much better.

Research: **** Practice: $* * * *$ Originality: $* \quad$ Readability: $* * * *$ Ref: 7408

\section{Towards understanding the attitudes of consumers who use internet banking services}

R. H. Walker and L. W. Johnson

SURVEY. Journal of Financial Services Marketing (UK), Vol. 10, No. 1, p. 84 (11pp)

Describes a survey of 180 randomly chosen face-to-face interviewees, of whom 124 were regular users of internet banking services, the purpose being to explore the relationship between such use and attitudes towards

\section{Banking, internet, consumers}


the service provider. Postulates two hypotheses: that regular internet use is positively related to a sense of relationship with the service provider; that such use is negatively related to a preference for face-to-face interaction. Finds that neither hypothesis is correct: many users felt themselves forced into using the internet service, either by their personal circumstances or by problems (eg queuing) at the bank. Thus there was a feeling of 'having to use' rather than 'preferring to use', and that use was imbued with negative attitudes towards the bank. Finds that regular use may continue despite dissatisfaction with the online service experience. Distinguishes between behaviour (eg use of a service) and attitudes. Advocates much greater care in ensuring that websites and systems are designed from a user perspective, to allow for quick and efficient working with freedom from clutter and confusion. Concludes that a preference for personal interaction remains strong even among regular internet users, and recommends that ways be found to compensate for the lack of faceto-face contact on the web.

The findings are, on the whole, in line with intuition.

Research: ** Practice: $* * \quad$ Originality: * Readability: *** Ref: 7409

\section{Internet \\ communities, ethics}

\section{Internet community forums: An untapped resource for consumer marketers}

\section{A. Pitta and D. Fowler}

THEORETICAL. Journal of Consumer Marketing (UK), Vol. 22, No. 5, p. 265 (10pp)

Notes the early use of the internet as an advertising medium, resulting in customer irritation and declining response. This was followed by the growth of one-to-one communications, especially in B2B. Notes use of the internet for research - but comments that all of this activity simply transferred traditional methods to the virtual world. Holds that online communities, by contrast, involve different ways of interacting, and of handling other communication disciplines such as PR and corporate communications; they also offer the opportunity for that most powerful marketing weapon, word of mouth. Notes the 'geography' of such groups, which is determined by shared interests or experiences, thus creating homogeneous groups, each different from the other. Describes the advantages, and dangers, of being, as a marketer, a participant in such a forum; deals with questions of ethics and etiquette in such circumstances. Points out that the participant should be a recognisable individual, not simple an interchangeable mouthpiece for 'the company'.

An introduction to a little-explored territory, full of opportunities and pitfalls. A hard-nosed contribution from someone who had been there, done that, would be even more instructive.

Research: * Practice: $* * *$ Originality: $* * \quad$ Readability: $* *$ Ref: 7410 
Internet, opportunities, threats

\section{E-marketing, international}

\section{Capitalizing on the internet opportunity}

G. S. Day and K. J. Bens

SURVEY. Journal of Business and Industrial Marketing (UK), Vol. 20, Nos 4/5, p. 160 (9pp)

Sets out to investigate how B2B firms view internet opportunities and threats, and who is most likely to gain from the internet. Details a survey of 165 (US) B2B respondents; the survey coded 15 ostensibly different consequences of the internet as either a disruptive or facilitating phenomenon. Reveals overall an optimistic view about the internet as a way of being more accessible to customers, tightening links with customers and reducing customer servicing costs through self-service. Finds, however, that the firms which see the greatest opportunities for strengthening customer relationships are those that are already much better at this than their rivals. Derives three lessons: the leaders will extend their lead; new market models (infomediaries, pricing models, reverse auctions, public exchanges) will have only a modest effect; the internet complements all other channels, rather than being just another additional channel. Emphasises the need for channel synchronisation; finds that early fears of channel conflict have largely dissipated.

The reassurance that the internet will not, after all, usher in red revolution may, like the earlier contrary view, be premature. Technology, which enables revolutions, moves fast; human beings, who alone create them, move slowly. The internet revolution has not happened - yet. But don't bet that it won't.

Research: $* * *$ Practice: $* *$ Originality: $* *$ Readability: $* * *$ Ref: 7411

\section{International e-marketing: Opportunities and issues}

\section{J. N. Seth and A. Sharma}

THEORETICAL. International Marketing Review (UK), Vol. 22, No. 6, p. $611(12 \mathrm{pp})$

Holds that e-marketing is about reducing costs and/or increasing reach. Distinguishes four different types of economy that offer different opportunities and issues to e-marketers: A, those with high infrastructure development and high marketing institutional development (eg the USA and Hong Kong); B, those with high infrastructure but low marketing development (eg Japan and Germany); C, those with low infrastructure but high marketing development (eg Mexico and Brazil); D, those low in both categories. Proposes that in those countries in category A, e-marketing will focus on increasing reach and reducing marketing costs using brick-and-click strategies and/or product digitisation (airline and theatre ticketing etc); profitability will be low. In category B emphasis will be on disintermediation through third-party e-retailers, and profitability will be substantial. In category $\mathrm{C}$ buying groups will emerge and firms will extend e-marketing facilities to consumers; profitability will be low. In category $\mathrm{D}$ again firms will provide access, but mobile phones will become a prime marketing platform; profitability will be 
negligible. Assesses the impact of e-marketing on business practice: demand management will give way to supply management, mass marketing to customer-centric marketing, standardisation to personalisation. There will be a rise in product co-creation, universal rather than geographical availability and non-time-based transactions. Examines some managerial implications.

Despite the publisher's appalling failure to edit this text properly, it remains readable and, after a slow start, interesting and persuasive.

Research: $* * \quad$ Practice: $* *$ Originality: $* * * *$ Readability: $* *$ Ref: 7412

\section{Loyalty, behavioural, attitudinal}

\section{Exploring loyal qualities: Assessing survey-based loyalty measures} S. Rundle-Thiele

THEORETICAL. Journal of Services Marketing (UK), Vol. 19, No. 7, p. 492 (9pp)

Notes the wide concern in marketing literature to define and measure loyalty, centring on the distinction between attitudinal and behavioural loyalty. Considers developing historical views of loyalty. Defines loyalty as 'a customer's adherence or allegiance to an object'. Details a questionnaire-based survey of wine-club members and insurance customers to establish (through analysing the answers to 31 questions) what factors are inherent in loyalty. Claims the results demonstrate that there are six factors involved in loyalty: attitudinal loyalty, behavioural intentions; resistance to competing offers; propensity to be loyal; complaining behaviour; behavioural loyalty. Thus loyalty is more than one or two things, singly or combined; nor are the different factors progressive, sequential or hierarchical. Claims that attitudinal loyalty explains 30 per cent of total variance; resistance to competing offers 10 per cent; the other four factors 4-6 per cent each. Provides tables showing the questions used in the survey, and which of them (15 out of 31) are 'pure' measures of loyalty. Suggests loyalty may be contextspecific - eg different in situations of free choice, or renewal versus nonrenewal or continuing uninterrupted service.

The findings are sensible enough, but provoke a further question: if 'loyalty' is in fact six different things, each in any case context-related, why do we continue to use a single rather silly word to cover all of them?

Research: **** Practice: $* *$ Originality: $* *$ Readability: $* *$ Ref: 7413

\section{CRM: Conceptualisation and scale development}

L. Y. M. Sin, A. C. B. Tse and F. H. K. Yim

THEORETICAL. European Journal of Marketing (UK), Vol. 39, Nos 11/12, p. 1264 (27pp)

\section{CRM} describes it as an 'emerging discipline' needing further theoretical 


\section{Marketing, serendipity, luck, chance, Levitt}

development. Sets out to hypothesise the key dimensions of CRM and verify them via a series of three studies conducted with managers and MBA students in Hong Kong. Details the methodology of the studies, and how they produced a four-factor solution for the components of CRM: key customer focus; CRM organisation; knowledge management; technology-based CRM. Gives 18 'scale items' within these four components. Distinguishes between relationship marketing (strategic, emotional) and CRM (tactical, managerial). Defines CRM as 'a comprehensive strategy and process that enables an organisation to identify, acquire, retain and nurture profitable customers by building and maintaining long-term relationships with them'. Elaborates each of the four CRM components: key customer focus involves selection of key customers, assessment of lifetime value, personalisation and interactive co-creation marketing; CRM organisation involves cross-disciplinary teams and HR management; knowledge management means sharing and dissemination of knowledge; technology-based CRM refers to hardware and software systems.

The criticism of current CRM theory (or its lack) is merited, and the definitions and elaborations offered are unexceptionable so far as they go, echoing mostly what is accepted best practice. The three-part study is a sledgehammer to crack a nut.

Research: $* * \quad$ Practice: $* * \quad$ Originality: $* * \quad$ Readability: $* * *$ Ref: 7414

\section{Science, serendipity and the contemporary marketing condition}

\section{S. Brown}

JOURNALISTIC. European Journal of Marketing (UK), Vol. 39, Nos 11/12, p. 1229 (6pp)

Notes, with numerous famous examples, how chance, luck, good fortune and serendipity loom large in business life. Claims that marketing academics, textbooks and degree programmes behave as if luck did not exist: they live in a Newtonian deterministic universe - at the very time, ironically, when physical science is hooked on indeterminacy and discontinuity. Notes attempts, with game theory and contingency planning etc, to encompass uncertainty — but quotes Rescher: 'Life is what happens when you're not making plans.' Claims room for a science of serendipity: holds that luck (good and bad) is catching, and a selffulfilling function. Holds that things work because we believe in them the placebo effect is a reality. Claims that this applies to such devices as TQM, CRM, etc. Also, marketing's problem is that no one believes in it any more: it is ossified by academia and in mid-life crisis. Quotes Pasteur: 'Chance favours the prepared mind.' Refers to Levitt's famous article, 'Marketing myopia', in the Harvard Business Review which not only introduced the concept of customer-centricity, but also revealed the importance of chance: his readers followed one path — why have we neglected the other? 
Supermarkets, seniors, service sector
A superficially light-hearted article (clearly belief is not an adequate basis for winning at roulette, as many have found) - but don't suppose it isn't serious for all that. Think about it.

Research: * Practice: $* *$ Originality: $* * *$ Readability: $* * * * *$ Ref: 7415

\section{The three 'big issues' for older supermarket shoppers}

S. Pettigrew, K. Mizerski and R. Donovan

SURVEY. Journal of Consumer Marketing (UK), Vol. 22, No. 6, p. 306 (7pp)

Notes the increasing importance of the senior market in terms of numbers and disposable income. Sets out to examine what issues are important to older shoppers in Australian supermarkets. Describes the creation of six focus groups (four female and two male) subdivided by age (50-64 and $65+$ ), which yielded three key issues held by respondents to be both generally important and personally relevant: the demeanour of supermarket staff; the functionality of equipment such as trolleys; appropriate location of products. Describes the testing of these findings by a telephone survey with 505 participants over age 50 , which confirmed the importance of these issues. Concludes with a set of recommendations for supermarket managers in particular, and service sector managers in general, regarding consideration of the needs of senior customers.

Nothing at all startling, but the overall message needs to be understood throughout the service sector.

Research: $* * \quad$ Practice: $* * \quad$ Originality: $\longrightarrow$ Readability: $* * *$ Ref: 7416

\section{Does direct marketing need to have a direction?}

\author{
I. C. $\mathrm{L} . \mathrm{Ng}$
}

THEORETICAL. Marketing Intelligence \& Planning (UK), Vol. 23, No. 7, p. $628(8 \mathrm{pp})$

Notes that direct marketing is the fastest growth area in marketing, fuelled by a growing collection of personal data amid rising privacy concerns. Notes the high wastage rate implied in an average response of 2.61 per cent and the proliferation of vouchers, discounts, loyalty schemes - all inflating marketing costs and shifting the marketing focus towards selling activities. Claims that companies should spend more time, effort and money on making the firm accessible to the consumer, and on providing options which enable consumers to self-select. Gives example of a retailer in a ski resort that charges high prices, which are paid by (rich) visitors, but publishes discount tokens in the local newspaper for local inhabitants. Recommends the creation of an array of products and product variants to allow customers again to self-select: to do this differentiating product attributes must be clear (recommends conjoint analysis). Claims that once customers have self-selected, premium prices 


\section{Downsizing, downscoping, corporate reputation}

are available. Notes that the internet is a step is this direction - but it is only one medium. Holds that more attention should be given, across all media, to developing creative strategies to improve consumer access: the role of marketing should not be reduced to one of purely outward communication and selling.

Quite an attractive and counter-traditional perspective, although practical examples of this thesis in action are too few. But bears thinking on.

Research: $* \quad$ Practice: $* * * *$ Originality: $* * *$ Readability: $* * *$ Ref: 7417

\section{The impact of downsizing on corporate reputation}

\section{S. C. Zyglidopoulos}

THEORETICAL. British Journal of Management (UK), Vol 16, No 3, p. $253(7 \mathrm{pp})$

Quotes the literature as claiming that downsizing does not lead to improved financial performance. Finds it curious that despite this the practice continues. Distinguishes between downsizing (reducing the head count) and downscoping (eg selling off a whole department to another owner). Looks at 145 cases of downsizing in the USA and checks these against the AMAC survey in Fortune magazine, which rates corporations relative to competitors on eight attributes. Creates two hypotheses: that downsizing is positively correlated with losses in corporate reputation; that downsizing and downscoping have different effects on reputation. Finds both hypotheses upheld by study. Concludes that downsizing has higher potential for pain than gain.

An article which reinforces this reader's prejudices. The current fashion for downsizing has as much to do with rationality as a lemming's trip over the precipice.

Research: $* * * *$ Practice: $* \quad$ Originality: $* * * *$ Readability: $* *$ Ref: 7418

\section{Best face forwards: Improving companies' service interfaces with} customers

\section{J. F. Rayport, B. J. Jaworski and E. J. Kyung}

THEORETICAL, WITH EXAMPLES. Journal of Interactive Marketing (USA), Vol. 19, No. 4, p. 67 (14pp)

Notes the increasing shortage of skilled workers in service industries, together with growing customer demand. Points to the growing use of machines in front-office environments. Suggests this is a two-edged sword which can reduce costs and increase customer convenience - or exactly the opposite. Notes that multichannel customers spend more than single-channel customers, but decries the use of the term 'channel', implying a discrete linear progression; prefers concept of an interface system. Suggests the current front-end office revolution is a repeat of the 
substitution of machines for humans, first in industry and then in the back office. Gives examples (Border, REI, Rote-Aid, Amtrak, Bell Canada) of effective front-office automation, properly re-engineered, which drives increased sales and improved productivity, as well as one contrary example (United Airlines). Recommends that front-office re-engineering should consider substitution (of people by machines), complementarity (both working together) and displacement (outsourcing), depending on what is appropriate in each case. Holds up as a model QVC, which offers its customers ordering facilities via the web (10 per cent take-up), VRU (40 per cent) or human operator (50 per cent), all being internally integrated. (Points out that QVC is valued at 3.0 times revenue compared with Wal-Mart's multiplier of 1.0 or Sears's of 0.25.) Compares methodology (and results) of QVC with those of its main competitor, HSN. Suggests stepped programme for integrating activities, processes and systems.

As with earlier phases of automation, the USA has moved before Europe; here is an opportunity to learn some lessons ahead of time.

Research: $* * *$ Practice: $* * * *$ Originality: $* * *$ Readability: $* * *$ Ref: 7419

\section{IT, corporate governance}

\section{Information technology and the board of directors \\ R. Nolan and F. W. McFarlan}

THEORETICAL, WITH EXAMPLES. Harvard Business Review (USA), October 2005, p. 96 (11pp)

Claims that most companies suffer from a lack of board-level oversight of IT. Compares this situation with accepted standards in other areas of corporate governance where there are board committees - eg audit, compensation and governance committees - with understood roles and responsibilities. Identifies a number of large companies that have now created board-level IT committees. Claims that the question is not whether, but how, boards should be involved in IT decisions.

Distinguishes four modes of operation, representing different strategic impacts of IT: a support mode, which has relatively low reliability requirements and low need for new IT - motto, do not waste money (eg Zara, a Spanish clothier); a factory mode which is high on reliability need and low on new IT - motto, do not cut corners (eg a large East Coast medical centre); a turnaround mode with a high need for new IT and low need for reliability - motto, do not screw it up (eg American Airlines while developing its SABRE system); a strategic mode with a high need for both functions - motto, spend what it takes and monitor like crazy (eg Boeing). The first two modes operate 'defensive' IT; the latter two operate 'offensive' IT. Gives detailed criteria for all four modes. Gives list of questions, applicable to companies in each mode, to which boards should require answers. Recognises that not all companies should adopt the same systems for monitoring IT, and discusses different possible methods for each mode; gives, for those that need a board-level IT governance committee, a calendar of activities geared to a defensive or 
Organisation type, passive-aggressive, Symantec offensive IT strategy. Discusses the requirements for IT expertise in ensuring proper IT oversight, and recognises its shortage.

Raises but doesn't answer the question of the dog that didn't bark: why, 40 years after the introduction of computers in business, have so few IT 'experts' made it to the boardroom, and why are so many board members still computer illiterate?

Research: $* * *$ Practice: $* * * *$ Originality: $* * \quad$ Readability: $* * * *$ Ref: 7420

\section{The passive-aggressive organization}

G. Neilson, B. A. Pasternack and K. E. Van Nuys

SURVEY. Harvard Business Review (USA), October 2005, p. 82 (11pp)

Distinguishes seven different types of organisation, based upon an online survey of 30,000 employees with a further 20,000 face to face; these are characterised as resilient (17 per cent); just-in-time (10 per cent); military precision (4 per cent); fits-and-starts ( 8 per cent); outgrown (10 per cent); overmanaged ( 9 per cent); passive-aggressive ( 27 per cent). (The remaining 15 per cent were inconclusive.) Shows the contrasting proportion of persons in resilient and passive-aggressive organisations who agreed/disagreed with five significant statements about their companies, and how they rated their companies' relative profitability. Characterises passive-aggressive companies as being congenial and seemingly conflict-free, with easy achievement of consensus but struggling to implement agreed plans. Notes three major symptoms of this syndrome: unclear scope of authority; misleading goals; agreement without cooperation. Discusses each. Suggests that all unhealthy organisations suffer from a misalignment of four basic building blocks: ineffective motivators; unclear decision rights; the wrong information; misleading structure. Discusses each, with examples. Considers possible methods for tackling the disease: bring in new blood; leave no building block unturned; make decisions and make them stick; spread the word and the data; match motivators to contribution. Uses as example the case of John Thompson, new CEO at Symantec.

The quoted differences in responses are fascinating; the categorisation of organisations based on those responses (although the methodology is not explained in detail) is interesting; the resultant analysis is tolerably convincing.

Research: $* * *$ Practice: $* * \quad$ Originality: $* * \quad$ Readability: $* * * * *$ Ref: 7421 